\title{
PESQUISA DE ANTICORPOS CONTRA BVDV, EM SORO SANGUÍNEO DE FÊMEAS BOVINAS, PROVENIENTES DA REGIÃO DO VALE DO RIO DOS BOIS, GOIÁS, BRASIL
}

Mírianny Urzêda', Pedro Gonçalves Margon Ribeiro', Wesley José de Souza², Andréa Souza Ramos de Medeiros ${ }^{3}$, Carlos Frederico Martins ${ }^{4}$

1. Graduandos em Medicina Veterinária do Instituto Federal Goiano, Campus Urutai. (miriannyurzeda@hotmail.com) IF Goiano, Urutaí, Brasil.

2. Professor Titular do Departamento de Medicina Veterinária Preventiva e Reprodução Animal do Instituto Federal Goiano-Campus Urutai

3. Assistente de Suporte acadêmico do Setor de Viroses da Reprodução do Departamento de Medicina Veterinária Preventiva e Reprodução Animal Faculdade de Ciências Agrárias e Veterinárias UNESP- Campus de Jaboticabal

4. Médico Veterinário pesquisador do Núcleo de Sistemas de Produção Animal da EMBRAPA- Cerrados

Recebido em: 08/09/2015 - Aprovado em: 14/11/2015 - Publicado em: 01/12/2015 DOI: http://dx.doi.org/10.18677/Enciclopedia_Biosfera_2015_207

\section{RESUMO}

O presente estudo objetivou estimar a prevalência de anticorpos contra o vírus da diarreia viral bovina (BVDV) em animais não vacinados provenientes de rebanhos bovinos da microrregião do Vale do Rio dos Bois, no estado de Goiás, Brasil. Foram coletadas, entre janeiro e fevereiro de 2015, amostras de soro de 57 animais em 08 propriedades localizadas em 03 municípios desta região. Essas amostras foram submetidas ao teste de virusneutralização e, em cada propriedade avaliada, aplicouse um questionário epidemiológico para investigar possíveis fatores associados à infecção. Os dados obtidos foram analisados por meio de estatística simples (porcentagem de prevalência). A soroprevalência para o BVDV foi de 57,1\% em 57 amostras de soro. Dos municípios estudados, 100\% apresentaram, pelo menos, $50 \%$ de animais por rebanho classificados como soropositivos. Em relação aos fatores de risco, podemos destacar a constante importação de animais (machos reprodutores, em sua grande maioria da raça holandesa) provenientes do sul do país onde se encontra alta taxa de prevalência de animais PI (Persistentemente Infectado), além deste fator podemos destacar também a alta rotatividade do rebanho pela microrregião. Os resultados obtidos demonstram a expressiva disseminação do BVDV no rebanho bovino desta região.

PALAVRAS-CHAVE: BVDV. Vale do Rio dos Bois. PI. Virusneutralização.

\section{ANTIBODIES RESEARCH BVDV IN BLOOD SERUM FEMALE BOVINE, FROM VALLEY REGION RIVER OF BULLS, GOIÁS, BRAZIL}

\begin{abstract}
This study aimed to estimate the prevalence of antibodies against bovine viral diarrhea virus (BVDV) in unvaccinated animals from herds of micro-region of the Bulls River Valley in the state of Goiás, Brazil. They were collected between January
\end{abstract}


and February 2015, serum samples from 57 animals in 8 properties in three municipalities of this region. These samples were subjected to virusneutralization, and assessed each property, we applied an epidemiological questionnaire to investigate possible factors associated with infection. Data were analyzed using simple statistics (percentage of prevalence). The seroprevalence of BVDV was $57,1 \%$ in 57 serum samples. The municipalities studied, $100 \%$ showed at least $50 \%$ of animals per herd classified as HIV-positive. Regarding risk factors, we can highlight the constant importation of animals (breeding males, mostly holandezes) from the south of the country where high prevalence of $\mathrm{PI}$ animals (Permanently Infected), and this factor can highlight also the high turnover of the flock for micro. The results demonstrate the significant spread of BVDV in cattle in this region.

KEYWORDS: BVDV. Bulls River Valley. IP. Virusneutralization.

\section{INTRODUÇÃO}

A expansão da pecuária no Brasil tem mostrado sua importância como uma das principais fontes de receita do PIB nacional. O reflexo dessa expansão deve-se, entre outros fatores, aos programas de acasalamento dirigido utilizando a monta natural, a inseminação artificial e diversas outras biotecnologias de reprodução. Só que o sucesso das técnicas depende da saúde reprodutiva dos machos e fêmeas utilizados nestes programas, para obtenção de resultados satisfatórios (ASBIA, 2009).

A diarreia viral bovina (DVB) é uma doença, provocada por um vírus RNA da família Flaviviridae, género Pestivirus, espécies BVD-1 ou BVD-2 (ICTV, 2000). Encontra- se mundialmente distribuída e provoca perdas, que podem ser elevadas, em explorações de bovinos de carne ou de leite. A infecção natural de animais imunocompetentes com vírus da diarreia viral bovina (BVDV) é acompanhada da produção de anticorpos neutralizantes e encontra- se muitas vezes associada a problemas de natureza subclínica, embora aconteçam também síndromes agudas com manifestações de natureza hemorrágica, abortiva, respiratória, da glândula mamária que evoluem, em regra, com baixa mortalidade (BROWNLIE, 2002).

A infecção de fêmeas gestantes pode resultar em perdas embrionárias e fetais, como também em malformações congênitas, natimortalidade e nascimento de bezerros fracos e inviáveis. A infecção do feto antes de sua capacitação imunológica, entre os 40 e 120 dias de gestação, em muitos casos favorece a geração de bezerros imunotolerantes persistentemente infectados (PI) (GROOMS, 2004). Bovinos PI são considerados os principais disseminadores do vírus no meio ambiente, pois são comumente assintomáticos, sorologicamente negativos e eliminam o vírus de forma contínua em suas secreções e excreções (FULTON et al., 2005).

No Brasil, diversos estudos sorológicos têm sido realizados em várias regiões, demonstrando a ampla distribuição da infecção pelo BVDV no rebanho bovino. OLIVEIRA et al. (1996) realizaram o primeiro estudo sobre animais PI no Brasil, mostrando uma frequência de 1,2\%. Posteriormente, BOTTON et al. (1998) observaram um índice de 0,75\%.

Devido aos problemas associados à presença do BVDV nas explorações infectadas têm sido adotadas diversas estratégias de combate à doença, assentes sobretudo na vacinação, com ou sem a detecção e eliminação dos animais infectados (BROWNLIE, 2002). 
Ante a pouca abrangência e o pequeno número de informações sobre a infecção na microrregião do Vale do Rio dos Bois, estado de Goiás, o presente estudo teve como objetivos investigar a presença de anticorpos contra BVDV em fêmeas bovinas com mais de 24 meses, que estavam apresentando algum tipo de problema da esfera reprodutiva e identificar os possíveis fatores de risco associados à infecção nos animais e propriedades estudadas.

\section{MATERIAL E METODOS}

\section{Coleta de amostras e dados}

A colheita de amostras ocorreu entre janeiro e fevereiro de 2015. As propriedades foram escolhidas aleatoriamente dentre as que se inscreveram como propriedade parceira do projeto, o número de propriedades foi obtido através da disponibilidade de propriedades que estavam com algum animal apresentando problema reprodutivo na referida data. Dessa forma, foram selecionadas 08 propriedades, distribuídas em 03 municípios da microrregião do Vale do Rio dos Bois, estado de Goiás, Brasil.

Para a análise dos fatores potencialmente associados à infecção pelo BVDV, foram preenchidos questionários contendo informações referentes às propriedades e aos animais analisados. Os seguintes fatores foram avaliados: tipo de exploração (corte, leite ou mista), condições de criação (extensiva, confinada ou semiconfinada), tipo de ordenha (manual ou mecânica), uso de inseminação artificial, ocorrência de aborto, presença de outros animais domésticos e/ou silvestres, compra e venda de reprodutores, aluguel de pasto, uso de pasto em comum, utilização de piquete para parto/pós-parto, raça e idade.

A pesquisa de anticorpos neutralizantes foi realizada pelo teste de virusneutralização (VN), descrito no "Manual de Diagnóstico Testes e Vacinas para Animais Terrestres, Organização Mundial de Saúde Animal" (OIE, 2010) usando a estirpe BVDV-1 Singer proveniente da UNESP- Faculdade de Ciências Agrárias e Veterinárias Campus Jaboticabal- SP.

\section{Método Sorológico}

As amostras de sangue foram colhidas por punção da veia jugular externa ou veia sacral média, utilizando-se sistema a vácuo (Vacunteiner Becton-Dickson). No momento da colheita, as amostras foram deixadas em repouso em temperatura ambiente para retração do coágulo, e em seguida, foram transportadas sob refrigeração para o laboratório onde foram centrifugadas a 744 G durante 10 minutos, para separação do coágulo. O soro foi separado em alíquotas de $1 \mathrm{~mL}$ em tubos tipo Eppendorf®, e estocados à temperatura de $-20{ }^{\circ} \mathrm{C}$ até 0 momento da realização dos testes.

Para serem testados, os tubos foram descongelados, inativado o sistema complemento em banho-maria à temperatura de $56^{\circ} \mathrm{C}$ durante 30 minutos, e colocados em duplicata nas microplacas de 96 cavidades, foram utilizados em cada prova o controle do vírus e o controle de células MDBK.

\section{RESULTADOS E DISCUSSÃO}

Uma soroprevalência de 57,1\% para infecção pelo BVDV foi encontrada na população de fêmeas bovinas com mais de 24 meses, analisadas na microrregião do Vale do Rio dos Bois em Goiás. De acordo com a sintomatologia, as fêmeas 
estudadas foram divididas em duas faixas (Com queixa de aborto e sem queixa de aborto), sendo observado maior índice de positividade em fêmeas às quais os proprietários relataram ocorrência de aborto, do total de fêmeas analisadas, 85\% apresentavam essa sintomatologia.

Quanto à presença de outros animais junto com os bovinos, em 12,5\% das propriedades existiam ovinos e caprinos, em $87,5 \%$ havia suínos e em $100 \%$ foi relatada a presença de espécies silvestres. Do total de propriedades, $75 \%$ compravam reprodutores e $25 \%$ os vendiam; $50 \%$ praticavam aluguel de pasto; $50 \%$ não utilizavam pasto em comum com outras propriedades; $100 \%$ usavam piquete separado para fêmeas na fase de parto e/ou pós-parto.

Este foi o primeiro estudo que investigou a prevalência da infecção pelo BVDV de forma mais ampla nesta região e que relacionou os resultados de soropositividade com prováveis fatores de risco ou não para a infecção.

TABELA 1. Possíveis fatores de risco para a infecção pelo BVDV, avaliados no questionário das 08 propriedades.

Tipo de Exploração:

Condições de criação:

$100 \%$ Mista

Tipo de Ordenha:

Uso de inseminação:

Ocorrência de aborto (S/N):

Presença de outros animais domésticos e/ou silvestres $(\mathrm{S} / \mathrm{N})^{1}$ :

Compra e venda de reprodutores nos últimos 5 anos: $100 \%$ Extensiva 75\% Mecânica $100 \%$ Monta Natural $85 \%$ SIM

\begin{tabular}{l|r|l} 
& $25 \%$ & Relataram vender \\
\hline Aluguel de pasto (S/N): & $50 \%$ & SIM \\
\hline Uso de pasto em comum (S/N): & $50 \%$ & SIM \\
\hline Utilização de piquete para parto/pós-parto (S/N): & $100 \%$ & SIM \\
\hline Raça das vacas: & $100 \%$ & SRD \\
\hline Idade: & $100 \%$ & Entre 2 à 13 anos \\
\hline
\end{tabular}

1(S/N): (Sim ou Não)

Em relação aos fatores de risco da infecção para os animais, os resultados deste estudo, referentes à faixa etária, foram semelhantes aos encontrados por MAINAR-JAIME et al. (2001), os animais mais velhos apresentam índices mais elevados de prevalência de anticorpos, uma vez que tinham mais oportunidades de exposição ao agente e de induzirem a formação de anticorpos neutralizantes contra o BVDV, que persistem durante anos após a infecção. Por outro lado, outros autores que realizaram estudos similares não observaram diferença significativa da prevalência em relação à idade (QUINCOZES et al., 2007; TALAFHA et al., 2008).

Os resultados observados neste estudo, discordaram dos resultados encontrados por BRITO et al. (2010) que estudaram a prevalência da infecção pelo vírus BVDV em 3.533 fêmeas bovinas no estado de Goiás, no ano de 2002, onde foi observado associação entre a soroprevalência para o BVDV e aborto. Este resultado todavia, pode não corresponder à realidade, mas ser devido a respostas equivocadas presentes neste item do questionário. Este dado não exclui a possibilidade de associação destes problemas reprodutivos à outras doenças como por exemplo IBR e Leptospirose. 
Comparativamente aos estudos realizados anteriormente em Goiás (GUIMARÃES et al., 2001; BRITO et al., 2004), os índices se mostraram inferiores ou similares para rebanhos e municípios, confirmando que a infecção pelo BVDV se encontra disseminada nos rebanhos do estado, do mesmo modo que ocorre em outras regiões do país.

\section{CONCLUSÃO}

O elevado coeficiente de prevalência da infecção pelo BVDV encontrado no presente estudo aponta para a ampla distribuição desse agente na microrregião Vale do Rio dos Bois, estado de Goiás, Brasil, tornando evidente a necessidade de outras investigações para avaliar a extensão das perdas econômicas. Os dados obtidos poderão ser utilizados como subsídios para o estabelecimento de medidas efetivas de prevenção e controle da infecção no estado, o que contribuirá para o aumento da produtividade dos rebanhos. Neste sentido, sugere-se aqui a adoção de estratégias como a combinação entre a remoção gradual de animais infectados/PI e a realização de quarentena no ingresso de bovinos na propriedade, além de exames sorológicos anuais, buscando impedir a reintrodução de animais infectados no rebanho. Deve-se salientar também a importância da utilização de sêmen livre de BVDV e do uso de vacinas, que poderiam fornecer imunidade aos animais suscetíveis e reforçar a imunidade naqueles anteriormente infectados (BROCK, 2003; FLORES et al., 2005; QUINCOZES et al., 2007).

\section{REFERÊNCIAS}

ASBIA - Associação Brasileira de Inseminação Artificial. Relatório técnico anual. Disponível em <http://www.asbia.org.br>. Acesso: 25 de maio de 2015.

BROWNLIE, J.;Bovine virus diarrhoea virus: pathogenesis and control. In: Recent Developments and Perspectives in Bovine Medicine, Keynote lectures of the XXII World Buiatrics Congress. 24-30.2002.

BOTTON AS, SILVA AM, BRUM MCS, WEIBLEN R, FLORES EF. Antigenic characterization of Brazilian bovine viral diarrhea virus isolates by monoclonal antibodies and cross-neutralization. Braz J Med Biol Res 31: 1429-1438, 1998.

BRITO WMED, SOUZA, WJ, VIEIRA S, LINHARES DCL. Detecção de anticorpos contra o vírus da diarréia viral bovina em fêmeas de rebanhos leiteiros não vacinados, com histórico de problemas reprodutivos, no Estado de Goiás. Rev Patol Trop 33: 45-53, 2004.

BROCK KV. The persistence of bovine viral diarrhea virus. Biologicals 31: 133-135, 2003.

FULTON RW, BRIGGS RE, RIDPATH JF, SALIKI JT, CONFER AW, PAYTON ME, DUFF GC, STEP DL, WALKER DA. Transmission of bovine viral diarrhea virus $1 \mathrm{~b}$ to susceptible and vaccinated calves by exposure to persistently infected calves. Can $\mathbf{J}$ Vet Res 69: 161-169, 2005.

GROOMS DL. Reproductive consequences of infection with bovine viral diarrhea virus. Vet Clin North Am Food Anim Pract 20: 5-19, 2004. 
GUIMARÃES PLSN, CHAVES NST, SILVA LAF, ACYPRESTE CS. Freqüência de anticorpos contra o vírus da diarréia viral bovina em bovinos, em regime de criação semi-extensivo. Ciênc Anim Bras 2: 35-40, 2001.

ICTV, 2000. Seventh Report of the International Committee on Taxonomy of Viruses, 2000. Ed. M.H.V. van Regenmortel, C.M. Fauquet, D.H.L. Bishop, E.B. Carstens, M.K. Estes, S.M. Lemon, J. Maniloff, M.A. Mayo, D. J. McGeoch, C.R. Pringle, R.B. Wickner.

MAINAR-JAIME RC, HERRANZ BB, ARIAS P, VAZQUEZ R. Epidemiological pattern and risk factors associated with BVDV infection in a non-vaccinated dairy-cattle population from the Asturias region of Spain. Prev Vet Med 52: 63-73, 2001.

OIE. Office International des Épizooties. Manual of standards for diagnostic test and vacines. Disponível em: http://www.oie.int/fileadmin/Home/eng/Healths standards/tahm/2.04.13_IBR_IPV. pdf. Acesso em 8 de março de 2010.

OLIVEIRA LG, OLIVEIRA EAS, SILVA LHT. Presença de Pestivirus e anticorpos contra Pestivirus em soros e cultivos celulares. Arq Bras Med Vet Zoot 48: 513-521, 1996.

QUINCOZES CG, FISCHER G, HÜBNER SO, VARGAS GDA, VIDOR T, BROD CS. Prevalência e fatores associados à infecção pelo vírus da diarréia viral bovina na região Sul do Rio Grande do Sul. Semina Ciênc Agrar 28: 269-276, 2007.

TALAFHA AQ, HIRCHE SM, ABABNEH MM, AL-MAJALI AM, ABABNEH MM. Prevalence and risk factors associated with bovine viral diarrhea virus infection in dairy herds in Jordan. Trop Anim Health Prod 41: 499-506, 2008. 